\title{
Aproximações entre o monitoramento metacognitivo e a elaboração de portfólio em uma disciplina de Química Geral
}

\author{
Approaches between metacognitive monitoring and portfolio \\ elaboration in a General Chemistry discipline
}

\author{
Solange Wagner Locatelli ${ }^{1}$ \\ Natália Cristina Barbosa Alves ${ }^{2}$
}

\section{Resumo}

O presente artigo tem como objetivo verificar as possibilidades do uso do portfólio pedagógico associado ao monitoramento metacognitivo de Flavell (1979), por meio da autoavaliação e autorregulação propiciadas aos estudantes por essa ferramenta, mediadas por devolutivas e orientações dadas constantemente pela docente. Foi feito um estudo de caso de um estudante da Universidade Federal do ABC ao longo de uma disciplina de Química Geral. Foram analisados os registros semanais feitos pelo aluno após cada aula, com suas percepções e autoavaliações e também observou-se o aproveitamento demonstrado nas duas provas aplicadas na disciplina. Os resultados indicam uma melhora de desempenho e de atitude do estudante, com sua participação ativa no processo, proposições de estratégias mais adequadas ao seu estudo e uma melhor organização devido ao monitoramento metacognitivo proposto neste estudo. Assim, verificou-se que é possivel fazer a aproximação do uso dos portfólios em sala de aula com o referencial de John Flavell sobre o monitoramento metacognitivo e que o portfólio, assim como sua condução pela docente, teve uma participação positiva no processo de aprendizado dos conteúdos da disciplina de Química Geral pelo aluno analisado.

Palavras chave: portfólio; metacognição; ensino de química; John Flavell; estratégia metacognitiva

\begin{abstract}
This article aims to verify the possibilities of using the pedagogical portfolio associated with Flavell's (1979) metacognitive monitoring, through self-assessment and self-regulation provided to students by this tool, mediated by devolutives and guidelines given by the teacher. A case study of a student of the Federal University of $A B C$ was done during a General Chemistry discipline. The student's records were analyzed after each class, weekly, with his perceptions and self-assessments and the grades obtained in two tests applied in the discipline were observed. The results indicate an improvement in the student's performance and attitude, with his active participation in the process, with propositions of strategies more appropriate to his study routine and better organization due to the metacognitive monitoring proposed in this study. Thus, it was found that it is possible to approximate the use of classroom portfolios with John Flavell's reference to metacognitive monitoring and that the portfolio, as well as its conduction by the teacher, had a positive participation in the learning process in the discipline of General Chemistry by the analyzed student.
\end{abstract}

Keywords: portfolio; metacognition; chemical education; John Flavell; metacognitive strategy

\footnotetext{
${ }^{1}$ Universidade Federal do ABC | solangeufabc@gmail.com

2 Universidade Federal do ABC | nataliabc.alves@gmail.com
} 


\section{Introdução}

Embora seja desejável que os estudantes adentrem no ensino superior com amplo grau de autonomia na condução de seus estudos, isso nem sempre acontece adequadamente, sendo que diversos fatores contribuem para esse problema. $O$ ingresso na Universidade Federal do ABC (UFABC) se dá por meio do ENEM (Exame Nacional do Ensino Médio), em que estudantes com diferentes formações e provindos de lugares distintos formam o corpo discente na Universidade. A observação em sala de aula permite inferir que, grande parte destes estudantes ainda não consegue se organizar de forma a favorecer seus aprendizados e, é nesse contexto, que a proposta da utilização do portfólio nas aulas de Química Geral (Na UFABC essa disciplina é denominada de Transformações Químicas) pode auxiliar. Isso porque Bona e Basso (2013, p.399) acreditam que o portfólio atua "possibilitando um espaço de comunicação, autonomia e responsabilidade pelo próprio aprendizado", o que é, especialmente, relevante neste contexto, em que se tem a formação de turmas grandes, em torno de 90 alunos.

Tobias e Everson (2002) ressaltam a importância de que, inicialmente, um indivíduo saiba diferenciar o que ele sabe do que ele não sabe pois, como complementa Locatelli (2011), se o aluno nem sabe distinguir o que sabe do que não sabe, não consegue planejar seu aprendizado, passo importante para ele avançar no processo. Esse aspecto mencionado evidencia uma habilidade metacognitiva básica. Brown (1978) reforça essa ideia dizendo que, tão importante como o conhecimento sobre o que se sabe, é o conhecimento sobre aquilo que não se sabe, passo fundamental para que o aluno possa desenvolver autonomia e ter condições de buscar por soluções para melhorar seu aprendizado, no caso, em Química. Por isso torna-se crucial considerar estratégias em sala de aula que propiciem aos alunos a oportunidade de reconhecer e tomar consciência do seu processo cognitivo de aprendizagem, repensando sobre ele e o ressignificando.

Nesse contexto, 90 graduandos do $1^{\circ}$ ano da UFABC cursaram a disciplina de Química Geral durante 3 meses e elaboraram portfólios semanais. Importante ressaltar que o presente estudo compõe parte de uma maior investigação, acerca da utilização dos portfólios como estratégia metacognitiva pelos alunos. Como o objetivo é o de estabelecer uma relação entre o monitoramento metacognitivo e a elaboração do portfólio durante as aulas de química, optou-se por se fazer um estudo de caso, aprofundando na compreensão e estabelecendo as conexões (portfólio-monitoramento) a que se propõe este trabalho. Com isso, tem-se como objetivo geral, identificar e analisar aproximações existentes entre o processo de elaboração do portfólio e o monitoramento metacognitivo. Para proceder a essa análise, utilizou-se o referencial teórico do trabalho de John Flavell, o Modelo de Monitoramento Metacognitivo (Flavell, 1979), que será abordado na sequência. Assim, a pergunta que orienta essa investigação é a seguinte:

Quais as possíveis relações entre o processo de elaboração do portfólio e o monitoramento metacognitivo, no andamento de uma disciplina de Química?

\section{Metacognição e o monitoramento}

São muitas as definições de metacognição utilizadas no ensino de Ciências. Particularmente, consideramos a definição de Flavell (1976) que diz respeito aos aspectos de monitoramento e autorregulação de um processo cognitivo. Três anos mais tarde, Flavell 
(1979) estabelece que, para que haja o monitoramento de um processo cognitivo, vários fenômenos estão agindo e interagindo, quais sejam (figura 1):

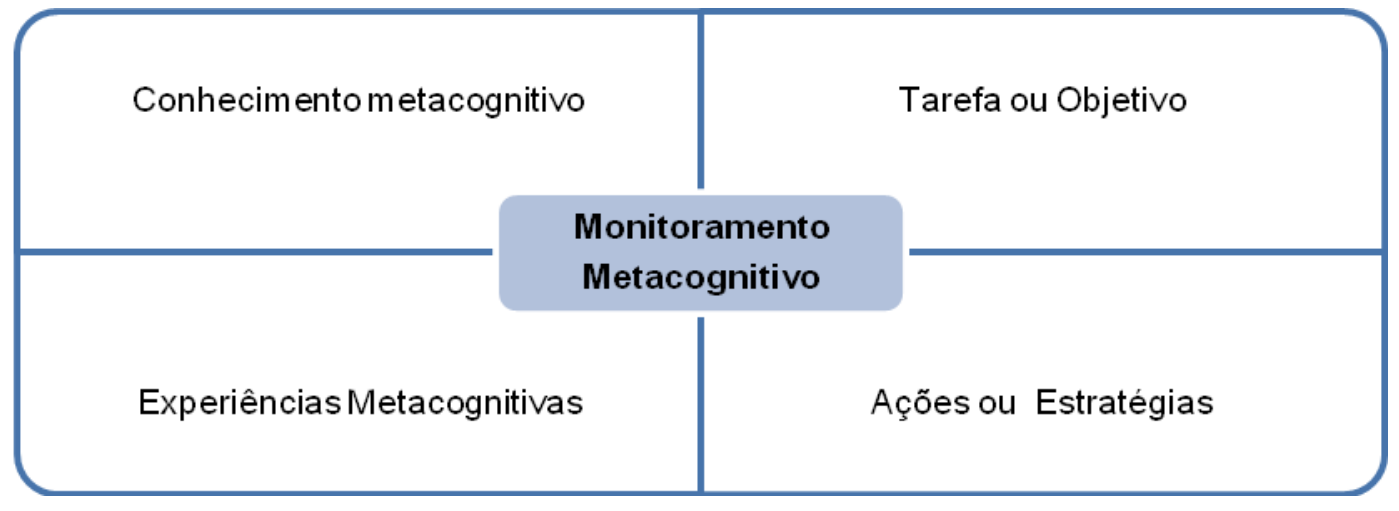

Figura 1: Quatro fenômenos interrelacionados ao monitoramento metacognitivo, segundo Flavell (1979).

Na sequência, serão tratados esses quatro fenômenos definidos por Flavell (1979), figura 1, que compõem o que ele denomina de monitoramento metacognitivo.

\section{Conhecimento metacognitivo}

Flavell (1979, p.907, tradução nossa) define como o "conhecimento ou crenças sobre que fatores ou variáveis agem e interagem e como isso afeta o curso e os resultados de um processo cognitivo. Existem três categorias principais desses fatores ou variáveis - pessoa, tarefa e estratégia".

O conhecimento metacognitivo da pessoa abrange o que alguém acredita sobre a sua natureza e pessoas (Flavell, 1979), ou seja, o conhecimento que se acredita possuir acerca da cognição envolvendo as pessoas, incluindo a si próprio.

Para facilitar o entendimento, vamos considerar alguns exemplos simples sobre o conhecimento metacognitivo da pessoa:

- Aprendo melhor fazendo mapas conceituais;

- Estudo melhor pela manhã;

- Preciso fazer exercícios para aprender;

São crenças ou julgamentos próprios sobre si mesmo, sendo que os exemplos referemse ao que Flavell (1979) denomina conhecimento metacognitivo intraindividual (do próprio indivíduo), havendo ainda os conhecimentos interindividual e o universal. Os dois últimos referem-se ao conhecimento que se acredita ter sobre outras pessoas (colegas, por exemplo) e sobre todas as outras pessoas (de forma mais geral) respectivamente.

O uso dos portfólios focaliza a atenção para o conhecimento intraindividual, convidando o aluno a repensar, constantemente, e a refletir sobre suas crenças préestabelecidas, como o conhecimento prévio que ele supostamente credita a si mesmo, suas formas de estudar, a melhor maneira de estudar, de se organizar, o tempo a ser investido, etc.

\section{Experiências metacognitivas}

Referem-se a "qualquer experiência afetiva ou cognitiva que acompanha e pertence a qualquer processo intelectual" (Flavell, 1979, p.906, tradução nossa). As experiências 
metacognitivas acontecem durante o processo, o aprendizado de química, por exemplo. Um aluno pode estar envolvido em uma aula de química e consegue reconhecer que talvez não tenha compreendido algo que acaba de ser discutido, ou seja, ele está no percurso cognitivo e conseguiu ter essa percepção. A utilização diária do portfólio propicia momentos para que isso aconteça e o aluno poderá ter a consciência sobre o seu processo cognitivo e refletir sobre ele, redirecionando seu aprendizado de forma mais eficiente.

Como o próprio Flavell (1979, p.906) pontua "conhecimento metacognitivo e experiência metacognitiva diferem entre outras coisas, somente no seu conteúdo e função, não na sua forma ou qualidade".

Assim, assume-se neste trabalho, que ambos são percepções/julgamentos que o indivíduo apresenta sobre algo cognitivo ou afetivo com relação a ele próprio ou a outras pessoas, sendo que o conhecimento metacognitivo seria uma avaliação após o processo ou parte dele, enquanto que as experiências são percepções vivenciadas durante o processo. Os exemplos seguintes auxiliam a ilustrar essa diferença:

- Conhecimento metacognitivo: Ao finalizar seus estudos, um aluno percebe que ainda não sabe alguns conceitos de química, suficientemente bem, para ter um bom desempenho em uma avaliação que será aplicada amanhã. Então, ele decide estudar novamente, reforçando alguns pontos.

- Experiência metacognitiva: O mesmo aluno tenta prever se entendeu bem os conceitos de química, o suficiente para ter um bom desempenho na avaliação. Então ele tenta descobrir fazendo perguntas a si mesmo sobre os conceitos e avaliando seu resultado a cada resposta.

\section{Objetivos ou tarefas a serem alcançados}

Como o próprio nome diz, são os "objetivos de um processo cognitivo" (Flavell, 1979, p. 907, tradução nossa). No caso, o objetivo do aluno é compreender conceitos de Química, durante a disciplina de Química Geral.

\section{Ações ou estratégias utilizadas}

Referem-se a "cognições ou outros comportamentos empregados para alcançar os objetivos" pré-determinados (Flavell, 1979, p. 907, tradução nossa). O uso dos portfólios, com a mediação da professora, propiciou vários momentos em que o aluno pudesse rever suas ações e estratégias para que mantivesse as que estivessem adequadas e modificando outras não tão eficientes para ele.

\section{Relação do monitoramento metacognitivo com a utilização do portfólio}

Esses quatro fenômenos descritos do monitoramento metacognitivo (FLAVELL, 1979) estão diretamente relacionados aos elementos presentes no processo de aprendizado em Química proposto na disciplina com a utilização dos portfólios, conforme ilustrado na figura 2.

Assim, com a utilização do portfólio, o aluno tem um espaço metacognitivo para se autoavaliar antes, durante e após o processo, monitorando, ativamente, seu conhecimento em Química. Pereira e Andrade (2012) consideram a autoavaliação como uma forma de promover o monitoramento e autorregulação dos processos cognitivos com o objetivo de ajudar na aprendizagem dos estudantes. 


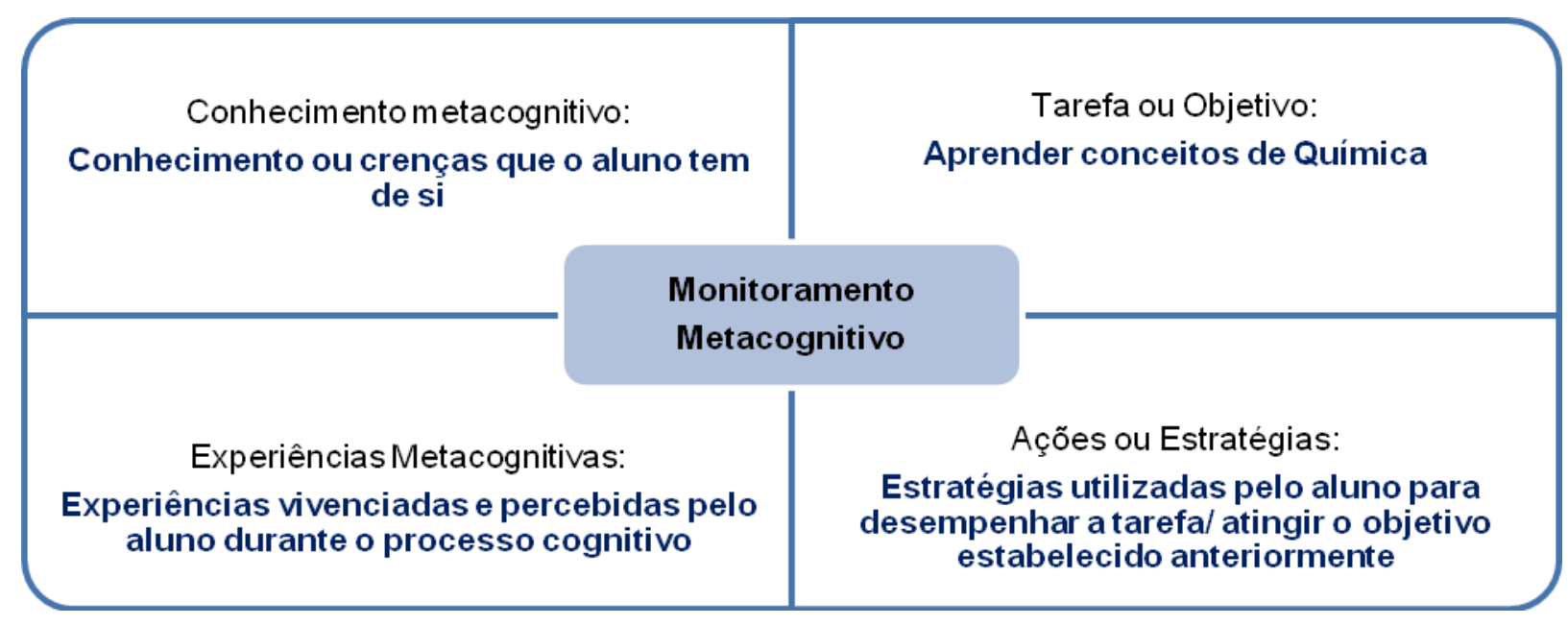

Figura 2: Aproximações/Relações entre o monitoramento metacognitivo (Flavell, 1979) e o processo de utilização dos portfólios na disciplina. Fonte: Autoria própria.

\section{Utilização de portfólios na aprendizagem e a metacognição}

O portfólio é um recurso incorporado das artes visuais, onde se faz um apanhado de trabalhos do artista, de forma a se obter um panorama global de seu estilo e técnicas (TANJ; SILVA, 2008). Em muitos dos trabalhos encontrados na revisão sobre portfólios aplicados para fins pedagógicos (ALVES, 2003; RANGEL; NUNES, 2006; TANJI; SILVA, 2008) é mencionado um modelo no qual o aluno, ou grupo de alunos, elabora seus próprios esquemas para compreensão do conteúdo, anotações pessoais sobre solução de problemas, conexões com outros temas, rotina de estudos, etc., complementado pelo que apontam Bona e Basso (2013, p.407) com relação ao seu aspecto central: "o Portfólio em si não é o foco, mas, sim, o que o estudante aprendeu ao produzi-lo, sob os olhos da avaliação reflexiva."

Portfólios têm sido utilizados como instrumento de avaliação do processo de ensinoaprendizagem. Segundo Rangel e Nunes (2006), esse tipo de avaliação apresenta caráter formativo e contínuo, fornecendo informações sobre a trajetória da aprendizagem. Evidencia, ao mesmo tempo, tanto para o educando quanto para o educador, os processos de autorreflexão (BONA; BASSO, 2013; TANJI; SILVA, 2008), contribuindo para uma avaliação mais completa da qualidade dos conceitos aprendidos, não deixando a avaliação apenas para momentos pontuais ao final de ciclos previamente estabelecidos, como as provas (RAPHAEL, 1995). Isso porque, de acordo com Locatelli (2017) o processo avaliativo deve assumir uma importante função reguladora com possível retomada do processo por todos envolvidos na aprendizagem: professores e alunos, reforçado por Gomes e Almeida (2016, p.58) quando referem-se à avaliação como componente importante da metacognição: "Outro componente importante é a avaliação ou reflexão sobre o resultado de sua aprendizagem e experiência. Esta atividade metacognitiva refere-se a um juízo global do produto de uma experiência de aprendizagem".

A elaboração de portfólios como ferramenta pedagógica surge na busca por aprofundar a compreensão e domínio do processo de ensino-aprendizagem, uma vez que o conteúdo a ser entendido não é transmitido, mas construído e refletido ao longo do tempo pelo estudante. Dessa forma, sua elaboração possibilita a aquisição de maior autonomia ao longo da formação, como vem sendo discutido por profissionais da educação 
nas últimas décadas em diversos países como Estados Unidos, Canadá, Portugal e outros na Europa (ALVES, 2003; TANJI; SILVA, 2008).

Esse formato traz potencialidades como treino da comunicação escrita, aquisição do costume de pensar, escrever e revisar com olhar crítico-reflexivo, incentivo ao uso da criatividade (TANJI; SILVA, 2008), assim como também desperta a consciência em relação a tudo que compõe o ambiente de estudo, as relações e vínculos que estabelece, reflexão sobre estratégias e atitudes favoráveis para desenvolvimento de habilidades e competências que contribuam para aquisição do conhecimento (RANGEL; NUNES, 2006) e, ainda, a utilização do erro como estratégia no processo de ensino-aprendizagem (BONA; BASSO, 2013).

Também são consideradas fragilidades, que podem ser contornadas, no que tange, principalmente, aos obstáculos iniciais à sua implantação como dificuldades na escrita e exposição dos esquemas e assimilações pessoais a outras pessoas, tal qual relatado por diversos autores (FROTA et al., 2011; NEVES et al., 2016; SANTOS; AGUIAR, 2016). Outro ponto ressaltado por Cotta, Costa e Mendonça (2015) é a questão do tempo envolvido nesse processo, tanto dos alunos ao elaborarem, quanto dos professores ao fazerem apontamentos. Os próprios autores sugerem que, para contornar esse obstáculo, o professor deve anunciar a sua utilização e objetivos, desde o início das aulas, possibilitando ao aluno uma organização nessa direção.

Também é recomendado que o portfólio se torne parte integrante de todo processo, local em que serão registradas as aulas, as dúvidas, os anseios, as dificuldades, mostrando ao aluno que o portfólio poderá se tornar seu aliado nos estudos e não um algo a mais a ser feito. Os benefícios de utilização dessa ferramenta superam as dificuldades, como observado por Rangel e Nunes (2006) e apontam para um caminho natural de aquisição de confiança na elaboração do portfólio, à medida que se evidenciam melhorias em qualidade e conteúdo (TANJI; SILVA, 2008).

A análise do material produzido foi feita por meio da base de estudos de Flavell (1976, 1979) sobre metacognição, e suas contribuições para memória, escrita, leitura e resolução de problemas. Com base nessas contribuições, viu-se a relevância da inserção de tais estudos para a educação, uma vez que os processos mencionados envolvem, em sua maioria, processos de aprendizagem, suscitando a pesquisa em diversas áreas de ensino como encontrado na literatura (COTTA; COSTA; MENDONÇA, 2015; FIGUEIRA, 2003; RIBEIRO; 2003;).

Por meio desta pesquisa, intenciona-se aproximar os objetivos propostos pelo uso do portfólio no contexto em sala de aula com o modelo de monitoramento metacognitivo proposto por Flavell (1979), em que, por meio do portfólio, espera-se mobilizar o estudante a refletir sobre as singularidades e peculiaridades do próprio processo de aprendizado, uma vez que o instrumento irá auxiliar a visualização do trabalho como um todo, tornando possível a consciência sobre o que se sabe sobre si, sobre o que se tem a aprender, quais meios se dispõe para adquirir tal conhecimento e a refletir em como propor linhas de ação que auxiliem a atingir o objetivo, que é a aprendizagem de conceitos de Química.

Uma vez que o portfólio mantém o registro de todo o percurso de aprendizagem, as tentativas podem ser avaliadas pelo estudante como mais ou menos eficazes, processo que Flavell (1979) chama de autoavaliação, e esse tem a possibilidade de tomar decisões sobre manter ou mudar de estratégia, a fim de obter melhores resultados em relação à tarefa que pretende executar, processo conhecido como autorregulação. 
Finalmente, a periodicidade com que a devolutiva do processo é dada aos alunos, o feedback, varia com os estudos, dependendo do contexto em que se dá a pesquisa. Foram encontrados modelos bimestrais (PEREIRA; ANDRADE, 2012) e modelos trimestrais (BONA; BASSO; 2013) e em ambos os casos foi verificada uma melhora na qualidade dos portfólios em relação às observações feitas pelos alunos, chegando ao fim de um ano letivo mais conscientes sobre sua forma de assimilarem novos conhecimentos. No contexto da pesquisa aqui apresentada, as devolutivas foram semanais, momento em que a professora, após ler os portfólios, fazia comentários com orientações a serem pensadas/repensadas. Na conclusão de seu trabalho, Cotta, Costa e Mendonça (2015, p.573) afirmam que "o portfólio configurou-se como um método de ensino, aprendizagem e avaliação inovador e potencializador de competências cognitivas e metacognitivas."

\section{Metodologia}

Essa pesquisa é de cunho qualitativo e exploratório. Segundo Bogdan e Biklen (1994), a investigação qualitativa é de natureza descritiva, sendo também marcada principalmente por descrições e interpretações de atitudes e contextos complexos (STAKE, 2011). O foco deste trabalho foi o processo desenvolvido pelos alunos durante a elaboração dos portfólios e não, simplesmente, no desempenho das provas. Os portfólios foram utilizados na interpretação de experiências, situações e condições humanas, onde buscou-se compreender os motivos, aspirações, crenças e valores levados em consideração pelos alunos para a caracterização das relações, processos e fenômenos assimilados ao conteúdo. Portanto, devido à natureza complexa desses dados, cabe a análise qualitativa, pois esses não podem ser quantificados, nem reduzidos à simples operacionalização de variáveis (MINAYO, 1996; TANJI; SILVA, 2008).

\section{Contexto e sujeitos da pesquisa}

Na pesquisa qualitativa, nem sempre há possibilidade de pesquisar todos os indivíduos do grupo ou da comunidade que se deseja estudar, devido a diversos fatores. Nesses casos, utiliza-se o método da amostragem, que consiste em obter um juízo sobre o total, mediante a análise de apenas uma parte, a amostra, selecionada por procedimentos científicos (MARCONI; LAKATOS, 2003). A amostra deve ser representativa e suficiente para apoiar as conclusões e é definida como uma parcela convenientemente selecionada do universo (população), um subconjunto do universo. Para atingir os objetivos dessa pesquisa traçou-se a perspectiva de obter amostras menores, de forma que houvesse o aprofundamento necessário durante a análise dos dados e fosse possível analisar a complexidade, a especificidade e a diversidade de seu conteúdo (MINAYO, 1996).

Foi escolhida uma turma de 90 alunos do último ciclo do 1. ${ }^{\circ}$ ano da UFABC, no ano de 2017. Estes 90 alunos estavam cursando uma disciplina de Química Geral, que é obrigatória a todos eles. Como a turma é grande, a docente optou pelo uso do portfólio como uma maneira de auxiliá-los na aprendizagem e avaliar o andamento das aulas. Apesar da não obrigatoriedade de sua utilização, a maioria dos alunos passou a fazê-lo e, assim, resolveuse investigar se ele poderia constituir um instrumento metacognitivo que propiciasse monitoramento e autorregulação. Da turma de 90 alunos, 10 entregaram todos os portfólios realizados durante o curso para a professora após o término da disciplina, momento em 
que que foram convidados a participar, espontaneamente, da referida pesquisa. Desses 10 alunos, 1 foi escolhido (aluno R), aleatoriamente, para que fosse feita uma análise em maior profundidade. Vale ressaltar novamente que o presente trabalho é parte de uma pesquisa maior acerca da compreensão da relação existente entre a metacognição e o uso dos portfólios.

\section{Como foi feita a coleta e a análise dos dados}

Nas ciências humanas e sociais, a triangulação é utilizada para confirmar a cientificidade de pesquisas qualitativas, defendendo o emprego múltiplo e variado de métodos na realização da pesquisa. Tal abordagem surgiu na década de 50, em estudos realizados na psicologia, e foi popularizada na década de 80 (BASSO JUNIOR et al., 2015). É importante por permitir que o investigador seja capaz de obter maior certeza de suas análises, utilizando diversos métodos, reunindo dados de maneiras distintas e examinandoos, a fim de que possam ser aproveitados por outros pesquisadores para estudos similares (FLICK, 2009).

Com relação ao aluno $\mathrm{R}$, foram recolhidos 9 portfólios escritos em papel, 2 reflexões enviadas em formulário google forms e foi feita uma entrevista semiestruturada. Os portfólios, propriamente ditos, consistiam na entrega das anotações/percepções das aulas e uma autoavaliação, semanalmente. Nesta autoavaliação, o aluno deveria refletir sobre a aula e seu aprendizado naquele conteúdo específico de química. Os formulários online foram referentes às reflexões realizadas após as provas e, finalmente, a entrevista auxiliou a esclarecer dúvidas após as análises. Sendo assim, caracterizam-se os elementos necessários para a triangulação dos dados.

Em pesquisa qualitativa narrativa (CRESWELL, 2007), a organização dos dados para análise se dá por meio da criação de categorias a partir de palavras ou frases que indicam padrões de pensamento, comportamento, ou relatos de acontecimentos (BOGDAN; BIKLEN, 1994). Determinadas questões relativas ao foco da pesquisa guiaram a criação de tais categorias, por meio da interpretação dos dados obtidos, de forma a agrupar os dados semelhantes de acordo com os padrões encontrados.

A partir de sucessivas leituras dos registros dos portfólios, à luz do referencial teórico de Flavell (1979), buscou-se referências de conteúdo as quais se pudesse relacionar aos conceitos:

- Conhecimento metacognitivo - como sendo as percepções ou sentimentos que o aluno considera de si mesmo após o processo (parcial ou total);

- Experiências metacognitivas - referentes as percepções e sentimentos que o aluno identifica durante o processo;

- Ações ou Estratégias - a forma como o aluno escolheu estudar;

- Tarefa ou objetivo - aprender Química.

\section{Resultados e discussão}

\section{Antes da realização da $1 .{ }^{a}$ prova (P1)}

Os registros que compreendem o período anterior à realização da P1 foram expressos pela realização e entrega de 5 portfólios com os resultados expressos no quadro 1: 


\begin{tabular}{|c|c|c|c|c|}
\hline \multicolumn{2}{|c|}{ Registros } & \multirow[t]{2}{*}{ Conhecimento metacognitivo } & \multirow{2}{*}{$\begin{array}{c}\text { Experiência } \\
\text { Metacognitiva }\end{array}$} & \multirow[t]{2}{*}{ Estratégia } \\
\hline Aula & $P^{3}$ & & & \\
\hline 1 & 1 & Julga não saber química o suficiente & $\begin{array}{l}\text { Acredita que o apoio da } \\
\text { professora pode ajudar }\end{array}$ & Atividades \\
\hline 2 e 3 & 2 & $\begin{array}{c}\text { Assume ter dificuldade em balancear } \\
\text { equações químicas }\end{array}$ & $\begin{array}{l}\text { A matéria está mais } \\
\text { difícil }\end{array}$ & Não propôs \\
\hline 4 & 3 & $\begin{array}{l}\text { Dificuldade para entender as reações } \\
\text { químicas e montar equações iônicas }\end{array}$ & Conseguiu acompanhar & $\begin{array}{l}\text { Vídeos e } \\
\text { exercícios }\end{array}$ \\
\hline 5 & 4 & $\begin{array}{l}\text { Dificuldade na nomenclatura das } \\
\text { entalpias e considerou a lista difícil }\end{array}$ & a aula e entender & Pesquisa \\
\hline 6 & 5 & $\begin{array}{c}\text { Acha que consegue fazer os exercícios, } \\
\text { mas ainda confunde entalpia. }\end{array}$ & $\begin{array}{l}\text { Matéria muito } \\
\text { complicada }\end{array}$ & Não propôs \\
\hline
\end{tabular}

Quadro 1: Síntese das percepções e estratégias demonstradas nos portfólios 1 a 5 do aluno R realizados durante a disciplina de Química Geral, antes da P1.

O aluno R começou a disciplina ansioso por acreditar que não saberia química o suficiente, devido a defasagens em sua formação no Ensino Médio e ainda relatou nunca ter estado em um laboratório de Química antes. Durante a primeira aula, sentiu-se mais tranquilo, em razão de perceber que poderia sanar essas dificuldades com a ajuda da professora da disciplina, conforme pode ser observado em sua fala: "Fiquei muito mais tranquilo após conhecer a professora, se mostrou extremamente preocupada com os alunos, além de ser calma e não ter pressa para passar o conteúdo" (Aluno R). Esse tipo de fala também foi encontrado nos resultados do estudo sobre o uso de portfólios no ensino de ciências realizado por Pereira e Andrade (2012), o que mostra que a condução da professora em relação à realização do portfólio pode passar uma maior segurança para os alunos. A experiência do professor deve auxiliar nesse sentido, uma vez que o portfólio pode, e nos casos estudados é utilizado como uma das ferramentas avaliativas. Sendo assim, devem-se prever as ações na atividade docente que despertem a capacidade dos estudantes em confeccionar os portfólios (BONA; BASSO, 2013).

A atividade proposta como estratégia no quadro 1, referente ao $\mathrm{P}-1^{5}$, foi apresentada pela professora. Na devolutiva deste primeiro portfólio ( $\mathrm{P}-1$ ) a professora sugeriu, como linha de ação, que o aluno assistisse vídeos sobre os assuntos que ele manifestou ter dificuldades.

Nas aulas 2 e 3, que correspondem ao portfólio 2 (P-2), o aluno R já consegue reconhecer dificuldades pontuais no seu processo, todavia ainda não propõe linhas de ação, o que foi sugerido pela docente na devolutiva, para que ele pensasse sobre quais estratégias poderiam ser efetivas para ele. A sugestão estaria relacionada ao conhecimento metacognitivo sobre a pessoa, quando se fala em conhecimento intraindividual, e sobre a tarefa a ser realizada (resolver exercícios).

Na aula 4 (P-3) e na aula 5 (P-4), o aluno R continua identificando seus obstáculos, já conseguindo acompanhar melhor as aulas e, sobretudo já tem a iniciativa de propor linhas

\footnotetext{
${ }^{3} \mathrm{P}=$ portfólio

${ }^{4}$ O objetivo (processo cognitivo) é o de aprender conceitos em Química.

${ }^{5} \mathrm{P}-1=$ portfólio 1
} 
de ação, como listas de exercícios, vídeos e pesquisa, o que evidencia uma melhora na sua autonomia. Percebe que as listas de exercícios e os vídeos parecem auxiliá-lo bem no acompanhamento das aulas, conforme seu relato: "Com a resolução das listas, estou conseguindo acompanhar o ritmo das aulas, os vídeos ajudaram bastante para ter uma base melhor, porém ainda tenho dificuldade para identificar quais substâncias são formadas depois de uma reação" (Aluno R). Nesta fala, importante ressaltar que ele consegue identificar, especificamente, onde residem seus problemas.

No P-5 (aula 6) o aluno demonstra preocupação e nervosismo com a complexidade dos conteúdos de Química a serem compreendidos, apesar disso, acredita que conseguirá realizar uma boa prova. Percebe que teve dificuldade em alguns exercícios da lista, mas não especifica qual o conteúdo: "A resolução da lista de revisão começou tranquila, e foi aumentando o grau de dificuldade, travei em alguns exercícios" (Aluno R).

\section{Período entre as provas (P1 e P2)}

Os registros que compreendem este período foram contabilizados por um formulário (F1) preenchido imediatamente após a P1 e a entrega de mais 4 portfólios com os resultados sumarizados no quadro 2:

\begin{tabular}{|c|c|c|c|c|}
\hline \multicolumn{2}{|c|}{ Registros } & $\begin{array}{l}\text { Conhecimento } \\
\text { metacognitivo }\end{array}$ & Experiência Metacognitiva & Estratégia \\
\hline \multicolumn{2}{|c|}{$F 1^{6}$} & $\mathrm{O}$ aluno $\mathrm{R}$ julgava que & Durante a P1 percebeu & Avalia as estratégias \\
\hline Aula & $P$ & $\begin{array}{c}\text { tinha estudado o } \\
\text { suficiente. }\end{array}$ & $\begin{array}{l}\text { que seu estudo foi } \\
\text { insuficiente }\end{array}$ & $\begin{array}{c}\text { utilizadas, focalizando } \\
\text { agora na resolução de } \\
\text { exercícios }\end{array}$ \\
\hline 8 e 9 & 6 & $\begin{array}{c}\text { Julga que as ideias não } \\
\text { estão claras. }\end{array}$ & $\begin{array}{c}\text { Durante a aula, ele } \\
\text { percebeu que não se } \\
\text { lembrava dos conteúdos }\end{array}$ & $\begin{array}{c}\text { Avalia que precisa de mais } \\
\text { empenho, retomar } \\
\text { conceitos, e realizar mais } \\
\text { exercícios. }\end{array}$ \\
\hline 10 & 7 & $\begin{array}{c}\text { Acredita ter } \\
\text { compreendido } \\
\text { equilíbrio químico }\end{array}$ & Sentiu a aula fácil & Fazer exercícios \\
\hline 11 e 12 & 8 & $\begin{array}{l}\text { Percebeu dificuldade } \\
\text { em deslocamento de } \\
\text { equilíbrio químico. }\end{array}$ & $\begin{array}{c}\text { Mesmo assim, continuou } \\
\text { sentindo a aula mais fácil } \\
\text { de compreender }\end{array}$ & $\begin{array}{c}\text { Continua focalizando nos } \\
\text { exercícios }\end{array}$ \\
\hline 13 & 9 & $\begin{array}{c}\text { Diagnosticou ainda } \\
\text { dificuldade em alguns } \\
\text { exercícios. }\end{array}$ & $\begin{array}{l}\text { Continua sentindo que } \\
\text { consegue compreender }\end{array}$ & $\begin{array}{c}\text { Continua focalizando nos } \\
\text { exercícios }\end{array}$ \\
\hline
\end{tabular}

Quadro 2: Síntese das percepções e estratégias demonstradas no formulário 1e nos portfólios 6 a 9 do aluno R realizados durante a disciplina de Química Geral, período entre a P1 e P2.

Percebe-se que, após a P1, o aluno R passou a se preocupar mais com as estratégias a serem utilizadas, sendo que em todas as aulas (8 a 13) demonstrou isso em seus portfólios (quadro 2, 4.a coluna). Isso porque, durante a P1 ele constatou que não tinha se preparado adequadamente, conforme seu depoimento: "Antes da prova achei que estava preparado e

\footnotetext{
${ }^{6} \mathrm{~F} 1$ = Formulário 1 preenchido após a realização da P1
} 
que as horas de dedicação seriam suficiente, mas durante a prova percebi que não tinha me aprofundado o bastante" (Aluno R). A reflexão em relação à importância das estratégias traçadas durante o registro no portfólio mostra que para o estudante, "cada resultado é um progresso mobilizador para continuar o estudo", como verificam Bona e Basso (2013, p.410).

A partir da aula 10 (P-7), o aluno R passa a ter a sensação de compreender as aulas, ainda que vivencie dificuldades, o que pode estar relacionado a escolha de uma estratégia melhor para alcançar seus objetivos, neste caso específico, com o foco na resolução de exercícios, em que pode ser observada a função regulatória propiciada pela autoavaliação do aluno R (LOCATELLI, 2017), no que tange à opção por outra estratégia, mais eficiente, para aprender Química. O aluno R nota que sua compreensão no decorrer das aulas tem evoluído, em concordância com uma fala sua no P-9: " Vendo o curso de transformações químicas de um modo geral, posso dizer que me desenvolvi bastante, desde a primeira aula onde estava com medo por não ter base" (Aluno R). Isso evidencia a confiança que o aluno $R$ foi construindo ao longo da elaboração do portfólio (RANGEL; NUNES, 2006). Essa fala também mostra que as estratégias, construídas ou reconstruídas pelo aluno, colaboraram para que tenha sido atingido o objetivo: aprender os conteúdos de transformações químicas. Como diria Flavell (1979): "Existe uma grande quantidade de conhecimentos que poderiam ser adquiridos, relacionado a quais estratégias seriam mais eficazes para atingir os objetivos em determinadas demandas cognitivas" (FLAVELL, 1979, p. 907, tradução nossa).

Após a realização da 2. ${ }^{a}$ prova (P2)

O registro que compreende este período foi o formulário (F2) preenchido após a P2 com os resultados resumidos no quadro 3.

\begin{tabular}{|c|c|c|c|}
\hline Registro & Conhecimento metacognitivo & Experiência Metacognitiva & Estratégia \\
\hline F2 & $\begin{array}{c}\text { Afirma achar que aprendeu } \\
\text { melhor os conteúdos. }\end{array}$ & $\begin{array}{c}\text { Diz ter sentido menos } \\
\text { dificuldade durante a P2 do } \\
\text { que a P1. }\end{array}$ & $\begin{array}{c}\text { Estudar assim para } \\
\text { as outras matérias. }\end{array}$ \\
\hline
\end{tabular}

Quadro 3: Síntese das percepções e estratégias demonstradas no formulário 1 e nos portfólios 6 a 9 do aluno R realizados durante a disciplina de Química Geral, período após a P2.

$\mathrm{Na}$ UFABC, o registro final da avaliação na disciplina é feito por meio de conceitos, do menor para o maior: F, D, C, B e A, assim como a atribuição do aproveitamento nas provas. $\mathrm{O}$ aluno $\mathrm{R}$ manifestou ter aprendido melhor os conteúdos, sentindo menos dificuldade na P2. Tal fato coincide com o desempenho observado nas avaliações, sendo que na P1 o conceito atribuído foi $C$ e na P2 o conceito foi $B$, o que pode ser mais um indício de melhora no aprendizado de química pelo aluno R. Esses resultados vão ao encontro aos observados por Cotta, Costa e Mendonça (2015, p.580), onde houve melhora no desempenho de alunos de graduação na área da saúde, notando que "pouco a pouco, os estudantes foram se empoderando, buscando novas fontes que subsidiassem suas reflexões, assumindo uma atitude mais responsável, comprometida, analítica e questionadora."

No final do curso, quando perguntado ao aluno R sobre os portfólios, ele afirmou que realizou todos eles e que ajudaram muito a estudar. Não demonstrou dificuldades para a entrega dos portfólios semanalmente: "Bom, tenho o costume de fazer resumos com as 
partes mais importantes das matérias antes das provas, apenas precisei entregar eles" (Aluno R).

A melhora no desempenho, advinda das estratégias traçadas e repensadas, bem como a tomada de decisão por seguir as estratégias mais eficazes, demonstra a autonomia adquirida pelo aluno R e para isso foi necessário analisar, sintetizar e avaliar as informações recebidas para aplicar o conhecimento adquirido nas avaliações do curso. Dessa forma, percebe-se a participação ativa e dinâmica do estudante, que toma consciência de seu processo de aprendizado e se sente motivado a continuar.

\section{Considerações finais}

Retomando a pergunta-problema da investigação - Quais as possíveis relações entre o processo de elaboração do portfólio e o monitoramento metacognitivo, no andamento de uma disciplina de Química? - pode-se observar que a utilização do portfólio propicia um meio facilitador para que o aluno possa refletir sobre seu aprendizado, no sentido que o convida a ser partícipe do seu processo de ensino-aprendizagem, com reflexão constante e contínua, denominado aqui de monitoramento metacognitivo. O aluno ingressante no ensino superior pode apresentar defasagens de conceitos conforme apresentado pelo aluno $\mathrm{R}$, e a tomada de consciência sobre isso é fundamental para uma reorganização dos estudos e proposição de estratégias mais adequadas para cada indivíduo, neste caso, com a focalização na realização de mais exercícios.

Tanto a reflexão sobre o conhecimento metacognitivo como as experiências metacognitivas possibilitaram ao aluno vivenciar suas dificuldades, localizando seus obstáculos e, assim, viabilizando um investimento mais direcionado ao que precisava ser aprimorado ou reconstruído. Vale ressaltar também, a grande valia da incumbência docente, proporcionando segurança, mediando o processo, dando devolutivas e avaliando o desempenho do aluno constantemente e ainda, a experiência com a elaboração das atividades que guiou o processo e também fez diferença. Todos esses elementos, somados aos resultados obtidos ao longo do processo, e não apenas pontualmente, motivaram o estudante a confeccionar o portfólio com mais empenho e a ter um olhar mais atento às estratégias utilizadas.

Por tudo isso, a aproximação do monitoramento metacognitivo proposto por Flavell (1979) com a utilização dos portfólios se mostrou altamente frutífera, no sentido de propiciar, intencionalmente, momentos de monitoramento com consequente autorregulação no aprendizado do aluno. Em todos os níveis escolares, sobretudo no superior, isso é crucial para o desenvolvimento da autonomia do indivíduo. Devido à vital importância disso no aprendizado dos graduandos, recomenda-se mais estudos metacognitivos que focalizem nos limites e possibilidades da utilização dos portfólios em sala de aula. 


\section{Referências}

ALVES, L. P. Portfólios como instrumentos de avaliação dos processos de ensinagem. Processos de ensinagem na universidade: pressupostos para as estratégias de trabalho em aula, v. 5, 2003.

BASSO JÚNIOR, A.F.; PERSCH, L.L.; KIEKOW, A.; SEBEN, P.S.; GUBERT, F.; TONDOLO, V.A.G. Triangulação: Uma Ferramenta de Validade e Confiabilidade. SINERGIA-Revista do Instituto de Ciências Econômicas, Administrativas e Contábeis, v. 20, n. 1, p. 19-28, 2016.

BOGDAN, R. C.; BIKLEN, S. K. Investigação qualitativa em educação: uma introdução à teoria e aos métodos. Tradução Maria João Alvarez. Portugal, Porto Editora, 1994, 355p.

BONA, A.S.; BASSO, M.V.A. Portfólio de Matemática: um instrumento de análise do processo de aprendizagem. Boletim de Educação Matemática, v. 27, n. 46, p. 399-416, 2013.

BROWN, A. L. Knowing when, where, and how to remember: A problem of metacognition. In: Glaser, R. (Org.), Advances in instructional psychology, Hillsdale, N.J.: Erlbaum, 1978, p.77165.

COTTA, R.M.M.; COSTA, G, D.; MENDONÇA, E.T. Portfólios crítico-reflexivos: uma proposta pedagógica centrada nas competências cognitivas e metacognitivas. Interface: comunicação, saúde e educação, v.19, n. 54, p.573-588, 2015.

CRESWELL, John W.; Qualitative Inquiry \& Research design: choosing among five approaches. Sage Publications: California, 2007, 395p.

FIGUEIRA, A. P. C. Metacognição e seus contornos. Revista Iberoamericana de educación, 2003.

FLAVELL, J. H. Metacognitive aspects of problem solving. In: RESNICK, L. B. (Org.). The nature of intelligence. Hillsdale, N.Y.: Lawrence Erlbaum, 1976, p. 231-235.

FLAVELL, J.H. Metacognition and cognitive monitoring: A new area of cognitivedevelopmental inquiry. American psychologist, v. 34, n. 10, p. 906-911, 1979.

FROTA, M. M. A.; MENEZES; L. M. B. D.; ALENCAR, C. H.; JORGE, L. D. S.; ALMEIDA, M. E. L. D. O portfólio como estratégia facilitadora do processo de ensino-aprendizagem para a formação em odontologia: Adequação de metodologias de ensino utilizando o ambiente virtual de aprendizagem. Revista da ABENO, v. 11, n. 1, p. 23-28, 2011.

GOMES, A.S.A; ALMEIDA, A. C. P. C. Letramento científico e consciência metacognitiva de grupos de professores em formação inicial e continuada: um estudo exploratório. Amazônia: Revista de Educação em Ciências e Matemática, v.12, n.24, p.53-72, jul. $2016 .$.

LOCATELLI, S.W. A análise da manifestação de elementos de metavisualização na aprendizagem de Química. Dissertação - Universidade de São Paulo - São Paulo, 155p, 2011.

LOCATELLI, S.W. A percepção de graduandos acerca de um processo avaliativo em práticas de ensino de Química - é possível avaliar de forma diferente? Revista Docência do Ensino Superior, v.7, n.2, p.13-33, 2017.

MINAYO, M.C.S Ciência, técnica e arte: o desafio da pesquisa social. Em Pesquisa social: teoria, método e criatividade. MINAYO, M.C.S (Org). Editora Vozes, 5. ed. 1996. 
NEVES, A.S.C.; GUERREIRO, J.M. A.; DE AZEVEDO, G.R. Avaliando o portfólio do estudante: uma contribuição para o processo de ensino-aprendizagem. Avaliação: Revista da Avaliação da Educação Superior, v. 21, n. 1, 2015.

PEREIRA, M.M.; ANDRADE, V.A. Autoavaliação como estratégia para o desenvolvimento da metacognição em aulas de ciências. Investigações em Ensino de Ciências, v.17, n.3, p. 663674, 2012

RANGEL, J.N.M.; NUNES, L.C. O portfólio no ensino superior: práticas avaliativas em diferentes ambientes de aprendizagem. Pro-posições, v. 17, n. 3, p. 167-180, 2016.

RAPHAEL, H. S. Avaliação: questão técnica ou política? Estudos em Avaliação educacional, São Paulo, Fundação Carlos Chagas, n.12, jul./dez. 1995.

RIBEIRO, C. Metacognição: um apoio ao processo de aprendizagem. Psicologia: reflexão e crítica, v. 16, n. 1, p. 109-116, 2003.

SANTOS, D. A.; AGUIAR, M. G. G. O portfólio como instrumento didático: o processo de construção/constituição do "ser professor". Revista Docência do Ensino Superior, v. 6, n. 1, 2016.

STAKE, R.E. Pesquisa qualitativa: estudando como as coisas funcionam. Porto Alegre: Penso, 2011.

TANJI, S., SILVA, C.M.S.L.M.D. As potencialidades e fragilidades do portfólio reflexivo na visão dos estudantes de enfermagem. Revista de Enfermagem UERJ, v.16, n.3, p.392-398, 2008.

TOBIAS, S; EVERSON, H. T. Knowing what you know and what you don't: further research on metacognitive knowledge monitoring. Research Report n. 2002-3, College Entrance Examination Board: New York - USA, 2002. 